\title{
A Curriculum Model Based on the SIGITE Guidelines
}

\author{
Reza Kamali, Samuel Liles, Charles Winer, Keyuan Jiang, \\ and Barbara Nicolai \\ Purdue University Calumet, Hammond, Indiana, USA
}

\author{
kamalir@calumet.purdue.edu sliles@purdue.edu \\ winer@calumet.purdue.edu keyuan.jiang@calumet.purdue.edu \\ barbara.nicolai@calumet.purdue.edu \\ Executive Summary
}

This paper describes the process used by the Computer Information Technology Department at PUC (Purdue University Calumet) during a major curriculum review and revision to implement the curriculum model developed by the SIGITE Curriculum Committee (Curriculum, 2005). The process was based on the learning outcomes set forth by the SIGITE curriculum model and the result is a structure that could be used to build IT majors around the recommended IT core courses with the individual majors, which could be highly customizable and flexible. The curriculum allows for a primary track and a complementary secondary track built during the third and the fourth years of the student's study. This is a flexible and easy to maintain curriculum, which allows changes without major curriculum overhaul.

Keywords: SIGITE, curriculum development, information technology education, ABET

\section{Introduction}

This paper describes a process for developing an outcome based objectives model (Helps, Lunt, \& Anthony, 2005 ) for implementing an undergraduate computer information technology (CIT) curriculum. Outcome based objectives are an integral part of the ABET (Accreditation Board for Engineering and Technology) accreditation guidelines. The literature supporting information technology education (Aasheim, Lee, \& Reichgelt, 2005; Dark, Ekstrom, \& Lunt, 2005; Hazem et al., 2004; Said et al., 2004; Stockman, Chaytor, et al., 2004; Stockman, Christopherson, Said, \& Nyland, 2004) and supporting using outcome based objectives (Abernethy, Treu, Piegari, \& Reichgelt, 2005; Longenecker Jr. \& Feinstein, 2005 ) to define the graduating student, then the specific requisite knowledge, skills, and abilities (KSA's) of the student's primary focus area. A graduate of the program should have specific sets of KSA's spread across the curricula.

Material published as part of this journal, either on-line or in print, is copyrighted by the publisher of the Journal of Information Technology Education. Permission to make digital or paper copy of part or all of these works for personal or classroom use is granted without fee provided that the copies are not made or distributed for profit or commercial advantage AND that copies 1) bear this notice in full and 2) give the full citation on the first page. It is permissible to abstract these works so long as credit is given. To copy in all other cases or to republish or to post on a server or to redistribute to lists requires specific permission and payment of a fee. Contact Editor@JITE.org to request redistribution permission.
Utilization of this process model allows the specific academic unit (department, school, discipline) to easily identify and address accreditation goals. We first decide what skills the students will need for a given program, which, in turn, defines the specialization for the discipline. Courses are developed within the specialization to teach the specific skills. The implementation is a matter of select- 
ing the appropriate courses within the specialization that teach the desired skill set for the discipline. Designing a program is the last step in the process since the idea is to provide a flexible framework around which an individually tailored student major can be customized.

The Special Interest Group for Information Technology Education (SIGITE) is an accreditation development group comprised of academics, professionals, and industry within the Association of Computing Machinery (ACM) who are responsible for creating the guidelines and requirements contained in the Information Technology Education volume. For those readers who are aware of CC2001 ("Computing curricula 2001", 2001) and previous volumes of the Computer Science education accreditation guidelines this is a similar effort on the part of SIGITE. The process of creating the SIGITE guidelines are integral to a larger effort to update all of the volumes of engineering and technology education (Shackelford et al., 2004). When completed these guidelines will be accepted and utilized by ABET (Accreditation Board for Engineering and Technology) for accrediting programs.

The concept behind an outcome based objectives curriculum model is analogous to reading a story backwards. You end up defining the conclusion before constructing the plot. Based on the requirements of "what must be accomplished" we define what must be taught. Stepping sequentially through the process, a story of what a student needs as KSA's emerges.

\section{The Curriculum Development Process}

The process (see Figure 1) of creating the curriculum included meeting with specific industry subject matter experts, and reviewing the needs assessment of those industry experts and hiring agencies. Specific requirements for hiring graduates of the program were assessed by the industry panelists and cross referenced with the SIGITE knowledge areas. These diverse groups became the stake holders for the curriculum project. These knowledge areas were then adopted and incorporated into the curricula (Lawson, Lidtke, \& Price, 2004). Where appropriate current courses were adapted, or modified to create a seamless adoption of the curriculum. However, where required, new courses were created to satisfy the needs of the stake holders.

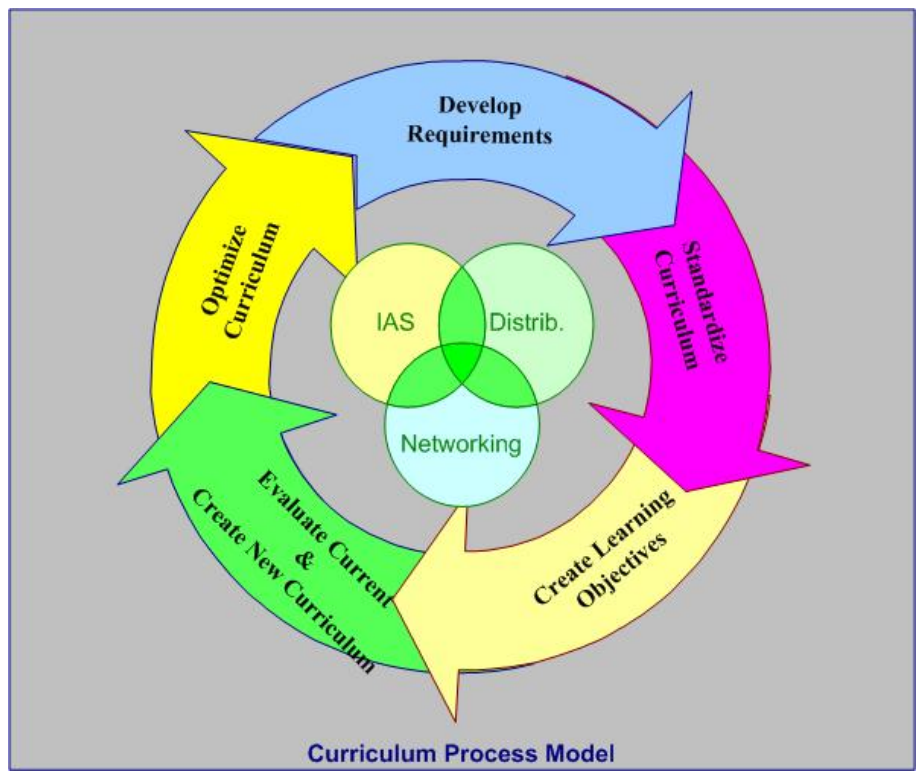

Figure 1 Curriculum Process Model and Structure (By Authors)

Each of the outcome based learning objectives of the courses was processed for level of skill

based on the Bloom Taxonomy (Anderson, Krathwohl, \& Bloom, 2001; Bloom, Krathwohl, Ma- 
sia, \& Emgelhart, 1956) for education. The objectives were then looked at for areas of expertise as applied to the individual curricula guidelines. Balance of instructional expectation was attained by ensuring that freshman and sophomore classes were balanced strongly towards the lower level of Bloom's taxonomy (Anderson, Krathwohl, \& Bloom, 2001; Bloom, Krathwohl, Masia, \& Emgelhart, 1956) with fewer upper level objectives. Consequently upper level courses have more higher-level objectives and fewer lower-level objectives with an expectation that prior courses prepared the student sufficiently. As part of the preparation of that expectation course designers met and built a map of the course objectives and knowledge requirements.

Before beginning the mapping of learning objectives the role of a student completing the course was discussed. What would a successful student from this program do as a career? Was the objective to create practitioners, scholars, or graduate school aspirants? These career objectives were addressed within the Computer Information Technology department. Figure 2 represents the structure that students may use to take the course work (Kamali, Liles, Winer, Jiang, \& Nicolai, 2005; Stockman, Chaytor, et al., 2004).

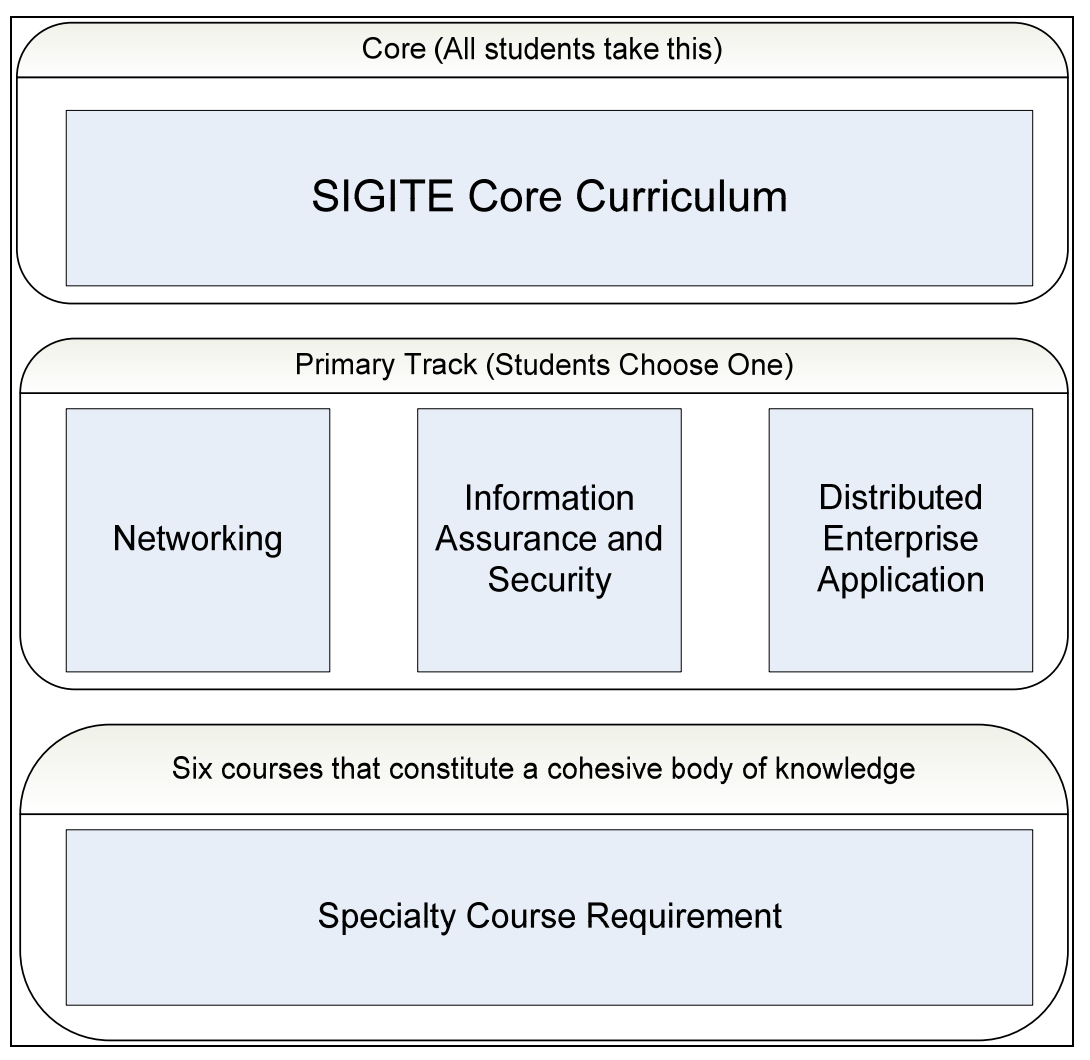

Figure 2 Modularized Curriculum Structure (Clusters)

The SIGITE core curricula (Curriculum: Proposed standards for IT curriculum, 2005), based on a modularized (clustered) model, was the foundation for developing the Computer Information Technology Department revised curricula. The core curriculum is made up of general education courses and specific Information Technology knowledge areas within the accreditation guidelines. The core courses span knowledge areas that include problem solving, algorithm development, database implementation, project management, human computer interaction, information assurance and security, networking technologies, platform technologies, and operating systems implementation. Most of these courses are found within the first two years of a four-year program and provide the foundation for later studies. Students taking the second two years will have a breadth of knowledge, skills, and abilities within the core discipline of information technology. 
Each student is required to select a specialization from one of the available options of a primary track (Distributed Enterprise Applications, Networking, Information Assurance and Security) and secondary track. The primary track specialization allows the curriculum to be customized to student's needs and identify the core interests of individual student. The primary track options can be added to as required by changing university and industry needs. Each primary track is capstoned by a course that is topical in nature, and customized to capture the new and emerging technologies of that specialization. This course is in addition to a senior design project which is a collective applications course that crosses the entire department and is intended to demonstrate student success in acquiring requisite knowledge. The secondary track(Stockman, Chaytor et al., 2004) is designed to complement the primary track chosen by each student. The secondary track is a collection of six courses that constitute a cohesive body of knowledge, which is considered to be a group of courses within a discipline, decided upon between the student and the adviser staff. The secondary track will allow for flexibility within the internal offerings of the Computer Information Technology department, and the ability for students to take courses outside of the department. Some examples of secondary track course topics would be bioinformatics, security, chemistry, business, physics, and metallurgy. These secondary track courses must compliment the primary area of study. For example bioinformatics compliments the Distributed Enterprise Applications track.

\section{The Implementation}

Utilizing the SIGITE accreditation document the faculty considered what a successful graduate should look like academically and professionally. A goal statement was developed reflecting the industry subject matter experts' suggestions and by current and past advisory committee members' needs. The goal statements were developed for the general aspects of an Information Technology graduate, and the specific aspects of a specialization. The following is representative of the goal statements for an information assurance and security student:

Upon graduation, a student is expected to

- be able to recognize and analyze the ethics and moral issues of securing networks

- evaluate and implement secure networks

- determine secure software practices

- evaluate and implement secure processes and procedures

- examine non-linear and psychological factors of technology abuse

- critique and audit software systems

- engage in forensic analysis of systems and software

- examine and determine best practices for confidentiality, integrity, and availability

The educational goals for Information Technology were drawn from the SIGITE specification (Curriculum, 2005) and the associated curricula development guidelines(Kamali, Liles, Winer, Jiang, \& Nicolai, 2005). The specializations were drawn up by the subject matter experts from industry and faculty. Sources such as classified job advertisements, labor department job descriptions and statistics, and the input from advisory board members were utilized. Each of the base requirements were clustered to find commonality between the requirements and a document was generated stating the expectations and career options for each specialization track for example: 
Information assurance graduating student possible career options:

- Chief Security Officers

- Network security technicians

- Security architects

- Public information security officers

- Network auditors

- $\quad$ Site certifiers

The common interests of each of the stakeholders were considered and specialization areas were defined. The areas of common interest are included in the core of the Computer Information Technology department's needs. Each individual educational requirement then was considered for specialization or secondary track inclusion. For instance a database specialist may need advanced modeling experience whereas a security specialist may only need minimal understanding of database topics. The definitive needs developed by the SIGITE specification for curriculum were integrated into the requirements of each stakeholder.

In balancing the specific educational and bureaucratic needs, one aspect was the requirement of Purdue University Calumet to meet the education and curriculum models approved by the University. For instance general education requirements must be met at the University for a program to be approved and implemented. These University requirements are derived from several levels of administration from local control to state board of higher education. One communications tool utilized was a matrix between the old curriculum and the new curriculum (Figure 3), showing the commonality and the differences where appropriate. This allowed all participants in the curriculum transition to have a point of reference for discussion.

Former CISIT students who are now in the CIT department should consult the following table in taking courses

\begin{tabular}{|c|c|c|c|c|c|c|c|c|c|}
\hline \multirow{4}{*}{$\begin{array}{l}\text { If You } \\
\text { Need }\end{array}$} & \multirow{4}{*}{$\begin{array}{c}\text { Instead, } \\
\text { Take }\end{array}$} & \multicolumn{8}{|c|}{ Offered } \\
\hline & & \multicolumn{4}{|c|}{ Fall } & \multicolumn{4}{|c|}{ Spring } \\
\hline & & \multicolumn{2}{|c|}{$\begin{array}{l}\text { Even } \\
\text { Year } \\
\end{array}$} & \multicolumn{2}{|c|}{$\begin{array}{l}\text { Odd } \\
\text { Year }\end{array}$} & \multicolumn{2}{|c|}{$\begin{array}{l}\text { Even } \\
\text { Year } \\
\end{array}$} & \multicolumn{2}{|c|}{$\begin{array}{l}\text { Odd } \\
\text { Year } \\
\end{array}$} \\
\hline & & D & $\mathrm{N}$ & D & $\mathrm{N}$ & $\bar{D}$ & $\mathrm{~N}$ & D & $\mathrm{N}$ \\
\hline ClS 103 & ITS 100 & $\sqrt{1}$ & & $\sqrt{ }$ & & & $\sqrt{ }$ & & $\sqrt{ }$ \\
\hline CIS 111 & ITS 120 & & $\sqrt{ }$ & & $\sqrt{ }$ & $\sqrt{ }$ & & $\sqrt{ }$ & \\
\hline CIS 140 & ITS 170 & & $\sqrt{ }$ & & $\sqrt{ }$ & $\sqrt{ }$ & & $\sqrt{ }$ & \\
\hline CIS 166 & ITS 240 & $\sqrt{ }$ & & $\sqrt{ }$ & & & $\sqrt{ }$ & & $\sqrt{ }$ \\
\hline CIS 187 & ITS 135 & & $\sqrt{ }$ & & $\sqrt{ }$ & $\sqrt{ }$ & & $\sqrt{ }$ & \\
\hline CIS 216 & ITS 240 & $\sqrt{ }$ & & $\sqrt{ }$ & & & $\sqrt{ }$ & & $\sqrt{ }$ \\
\hline CIS 217 & ITS 245 & & $\sqrt{ }$ & & $\sqrt{ }$ & $\sqrt{ }$ & & $\sqrt{ }$ & \\
\hline CIS 230 & ITS 170 & & $\sqrt{ }$ & & $\sqrt{ }$ & $\sqrt{ }$ & & $\sqrt{ }$ & \\
\hline
\end{tabular}

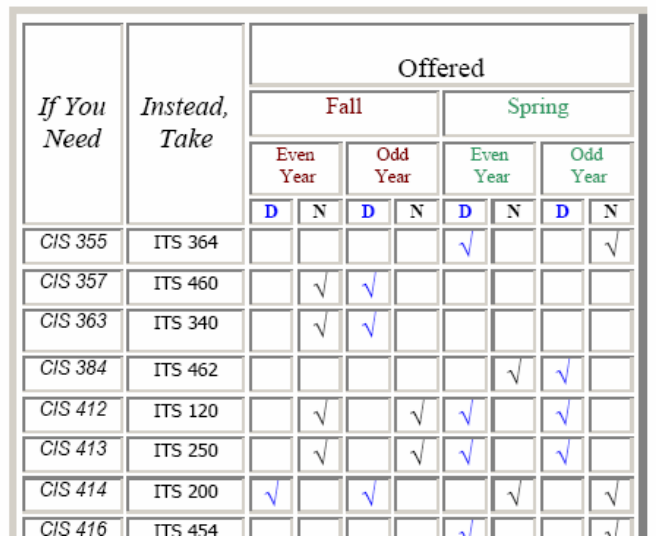

Figure 3 Course Substitution Matrix (Purdue University Calumet CIT Department, 2006)

Various industry entities were queried for input on the curriculum. In some cases individuals were specifically approached to advise on curriculum and to be part of the advisory committee for the department. Industry sources were researched along with the current information technology research (Dark, Ekstrom, \& Lunt, 2005; Hazem et al., 2004; Kamali, Liles, Winer, Jiang, \& Nicolai, 2005; Stockman, Chaytor, et al., 2004; Stockman, Christopherson, et al., 2004) in an effort to holistically address the issues of student employment or graduate school acceptance upon gradua- 
tion. Partnerships continue to be sought in an effort to expose students to a variety of opportunities and challenges within their field of specialization.

Specifically involving students in the process has the benefit of showing how students will react to changes in a curriculum. Surveys of students and discussion groups involving students allowed the faculty and administration to gauge interest in what was good with the old program and what enhances the value of the new program. Involving students in undergraduate research and promoting their participation in applied research activities adds another dimension to student learning. Perceived student interest around the adaptability of the new program to their needs has grown. The advisors and faculty interacting with students who are already in the program has shown colloquially that students are interested in moving to the new program.

The courses can be defined, designed, and developed around design structure utilizing the outcome based objectives as developed for each program. Pervasive themes of instruction ("Curriculum: Proposed standards for IT curriculum", 2005) were considered and adapted to the model. Pervasive themes would be defined for example as an information assurance and security concept that is introduced in one course, developed further in another course, and finally implemented without instruction in a final course. This format allowed for prerequisites and pervasive themes to be identified. Pervasive themes may be described as knowledge that isn't necessarily within the objectives or requirements of the curriculum.

Knowledge areas, which were defined and identified in each of the discipline specific areas, were considered to be the specific disciplines in the Information Technology specialty track. Adapting these knowledge areas to the framework that rapidly evolved allowed for courses to be seamlessly integrated into the overall architecture of the curriculum. This also enhances the flexibility of the curriculum to be modified, updated, or changed depending on prescient needs.

\section{Conclusion}

There is a synergistic strategy behind adopting the SIGITE based guidelines using a process based approach. Within the department's goals and requirements of accreditation this process allows for ease of meeting several departmental audit activities such as AQIP(Academic Quality Improvement Program, 2005) which is a university mandated audit. Outcome based curriculum development following this process provides a self documenting trail of learning objectives and assessment objectives for auditing (Rigby \& Dark, 2006). The outcome based objectives design also allows for discussion across the University resulting in collaborative efforts both in research and curriculum. The outcome based model enhances the opportunities for recruitment of new students and communication to perspective partners.

This process is a highly repeatable and flexible method of keeping a curriculum up to date. Further the process allows for an open communications style with stake holders and provides for a feeling of integrity between the faculty, administration and students within the process. In the end this process specifically addresses several of the systemic implementation issues found within university curricula adoptions strategies.

\section{References}

Aasheim, C., Lee, C. K., \& Reichgelt, H. (2005). Implementing the IT fundamentals knowledge area. Proceedings of the 6th Conference on Information Technology Education, Newark, NJ, USA.

Abernethy, K., Treu, K., Piegari, G., \& Reichgelt, H. (2005). A learning object repository in support of introductory IT courses. Proceedings of the 6th Conference on Information Technology Education, Newark, NJ, USA. 
Academic Quality Improvement Program. (2005). Retrieved December 10, 2005, from http://www.aqip.org/

Accreditation Board for Engineering and Technology. (2006). Retrieved May 20, 2006, from www.abet.org

Anderson, L. W., Krathwohl, D. R., \& Bloom, B. S. (2001). A taxonomy for learning, teaching, and assessing: A revision of Bloom's taxonomy of educational objectives (Abridged ed.). New York: Longman.

Bloom, B. S., Krathwohl, D. R., Masia, B. B., \& Emgelhart, M. D. (1956). Taxonomy of educational objectives: The classification of educational goals. New York: Longmans, Green.

Computing curricula 2001. (2001). Journal of Education Resources Computing, 1(3es), 1.

Curriculum: Proposed standards for IT curriculum. (2005). Retrieved from http://sigite.acm.org/activities/curriculum/downloads/IT\%20Volume-April\%202005.pdf

Dark, M. J., Ekstrom, J., J., \& Lunt, B., M. (2005). Integration of information assurance and security into the IT2005 model curriculum. Proceedings of the 6th Conference on Information Technology Education, Newark, NJ, USA.

Hazem, S., Russ, M., Soleda, L., Annu, P., Tamisra, S., Mark, S., et al. (2004). An implementation of a software development track in an information technology degree program. Proceedings of the 5 th Conference on Information Technology Education, Salt Lake City, UT, USA.

Helps, C. R. G., Lunt, B., M., \& Anthony, D. K. (2005). ABET accreditation with IT criteria. Proceedings of the 6th Conference on Information Technology Education, Newark, NJ, USA.

Kamali, R., Liles, S., Winer, C., Jiang, K., \& Nicolai, B. (2005). An implementation of the SIGITE model curriculum. Proceedings of the 6th Conference on Information Technology Education, Newark, NJ, USA.

Lawson, E., Lidtke, D. K., \& Price, B. (2004). Information technology accreditation activities. Proceedings of the 35th SIGCSE Technical Symposium on Computer Science Education, Norfolk, Virginia, USA.

Longenecker Jr., H. E., \& Feinstein, D. L. (2005). Development of assessment for undergraduate programs of information technology, and certification for program graduates. Proceedings of the 6th Conference on Information Technology Education, Newark, NJ, USA.

Purdue University Calumet CIT Department. (2006). CIS Course Substitution Table. Retrieved May 20, 2006, from http://www.calumet.purdue.edu/cit/students/current/CIS-ITS_Course_Equiv_1-06.pdf

Rigby, S., \& Dark, M. J. (2006). Using outcomes-based assessment data to improve assessment and instruction: A case study. SIGITE Newsletter, 3(1), 10-15.

Said, H., Chaytor, L., Humpert, D., Nyland, J., Schlemmer, R., Stockman, M., et al. (2004). An implementation of a core curriculum in an information technology degree program. Proceedings of the 5 th Conference on Information Technology Education, Salt Lake City, UT, USA.

Shackelford, R., Cassel, L., Cross, J., Impagliazzo, J., Lawson, E., LeBlanc, R., et al. (2004). Computing curricula 2004: the overview project. Proceedings of the 35th SIGCSE Technical Symposium on Computer Science Education, Norfolk, Virginia, USA.

Stockman, M., Chaytor, L., Humpert, D., Nyland, J., Schlemmer, R., Said, H., et al. (2004). An implementation of secondary tracks in an information technology degree program. Proceedings of the 5th Conference on Information Technology Education, Salt Lake City, UT, USA.

Stockman, M., Christopherson, C., Said, H., \& Nyland, J. (2004). An implementation of a networking track in an information technology degree program. Proceedings of the 5th Conference on Information Technology Education, Salt Lake City, UT, USA. 


\section{Biographies}

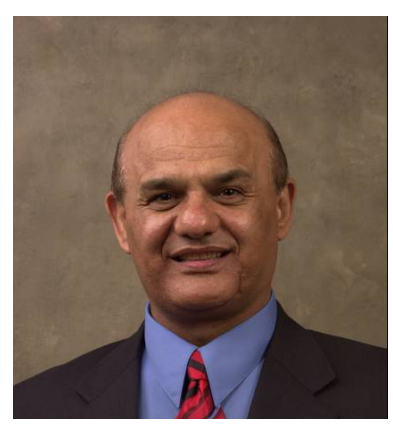

Reza Kamali, PhD, is an Associate Professor and department head of Computer Information Technology at Purdue University Calumet, Hammond, IN. He was a founding member and Education Officer of SITE, which later became ACM's SIGITE. Dr. Kamali was a member of The Joint Task Force for Computing Curricula 2005 and a member of IT 2006 Task Force.

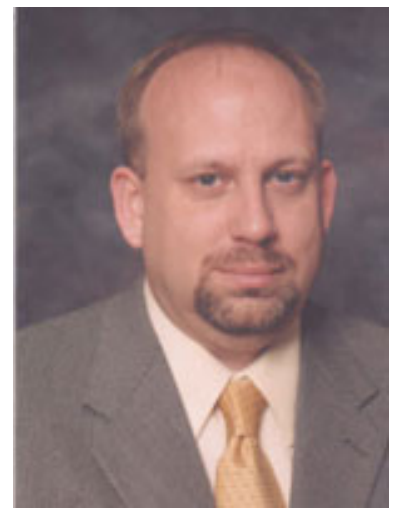

Assistant Professor Sam Liles M.S.C.S. is an information assurance and security researcher at Purdue University Calumet. Having worked as a senior networking consultant for NCR Corporation, Sun Microsystems, and MCIWorldcom his career has centered around designing and implementing sustainable secure enterprise and global networks. As a researcher at Purdue University he has spent much of his time investigating the linkages between information assurance and security topics and the pedagogy of information technology. His primary area of interest has been in the dissemination of high value information assurance and security pedagogical information. He is also interested in the intersection between education, ethics, and forensic analysis.

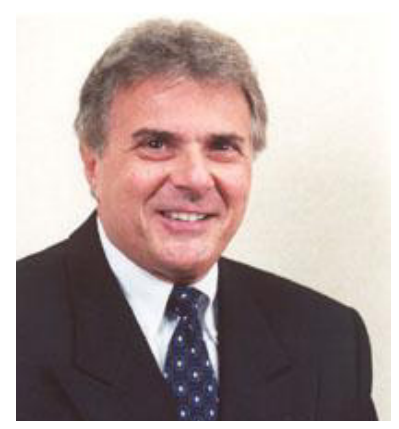

Charles (Chuck) Winer is Professor and past Acting Department Head of the Information Systems \& Computer Programming Department (now renamed the Computer Information Technology Department) at Purdue University Calumet. He joined the faculty of the University in 1983. His professional experience includes over thirty years of Information systems and information technology consulting in the areas of: Systems analysis and design, hardware and software evaluation (RFP \& contract considerations), developing systems and programming. He holds the $\mathrm{CDP} / \mathrm{CCP}$, and M.A. and B.A. degrees in business education/information systems from Governors State University. Chuck has published several articles in industry journals, presented papers at national and international conferences, been an invited keynote speaker at an international conference. During the 2000-2001 academic year, he was awarded the outstanding faculty service award by Purdue University Calumet. In addition to his teaching and research activities at the University, he is the principal of Winfo Data Systems, an IT consulting enterprise. 


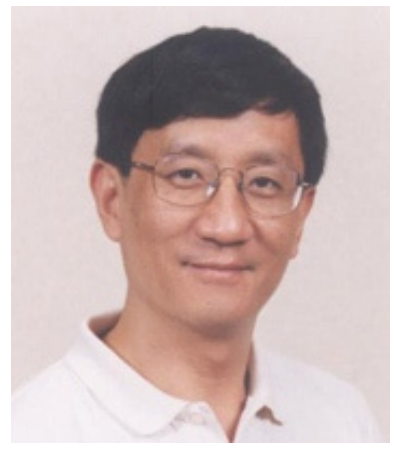

Keyuan Jiang is an Associate Professor of Computer Information Technology at Purdue University Calumet where he teaches software development. Since receiving his Ph.D. from Vanderbilt University, Dr. Jiang has been involved in delivering software solutions in biomedical and healthcare related field. His interest in biomedical computing also spans to bioinformatics. He is a senior member of the Institute of Electrical and Electronics Engineers (IEEE), and serves as an Associate Editor of the IEEE Transactions on Information Technology in Biomedicine.

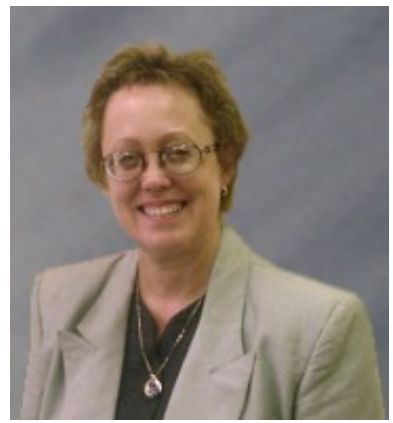

Barbara Nicolai is an Associate Professor in the Computer Information Technology Department at Purdue University Calumet (CIT). She joined the department at Purdue in 1998. Her professional experience includes over 30 years of business experience in the areas of Database Modeling, both Relational and Object-Oriented, Database Implementation. She has a B.A. Organization Management, Calumet College of St. Joseph, a Post Baccalaureate Certificate in Computer Information Systems from Purdue University Calumet, and a M.S. in Education, Instructional Design with an emphasis in Technology. She acts as database consultant for the senior project teams at Purdue University Calumet, CIT Department. Barbara's research statement is as follows: "My interests include one major area of study: Database Modeling and Design. My Body of Knowledge has been developed through professional work experience and academic degreed work. I am able to apply and direct my knowledge of database with my passionate interest of women in the technology field and women and children's health care. I combine these areas of interest to design and develop database models in the research of women, children and health care." 